\title{
Disseminação não consentida de imagens íntimas: uma análise jurisprudencial das compensações por danos morais
}

\author{
The non-consensual dissemination of intimate images: a case law \\ analysis of the compensation for moral damages
}

\section{Carolina Bouchardet}

Autora

carolinabouchardet@gmail.com

Bacharel em Direito pela PUC-Rio (2019), é advogada no escritório Eizirik Advogados. Foi pesquisadora voluntária (2016 e 2017) e bolsista (2018) do Programa de Iniciação Cientifica, na área de Direito Constitucional e estudos de gênero.

\section{Adriana Vidal de Oliveira \\ Orientadora \\ adrianavidal@puc-rio.br}

Doutora em Teoria do Estado e Direito Constitucional pela PUC-Rio (2012), recebeu menção honrosa no Prêmio CAPES de Tese em 2013. É coordenadora Acadêmica do Instituto de Direito da PUCRio desde agosto de 2018.

\section{Resumo}

Este trabalho pretende analisar criticamente o arbitramento, pelos tribunais de justiça do Rio Grande do Sul e de São Paulo, da compensação por danos morais sofridos por vítimas de disseminação não consentida de imagens íntimas. Após a análise do caráter de gênero dessa prática, serão expostos os dados encontrados na pesquisa jurisprudencial e, sob a luz da doutrina civil-constitucional, criticada a fundamentação dos tribunais.

Palavras-chave: disseminação não consensual de imagens íntimas; pornografia de vingança; pornografia não consensual; compensação; danos morais

\footnotetext{
Abstract

This paper aims to critically analyze the arbitration, by the courts of Rio Grande do Sul and São Paulo, of the compensation for moral damages suffered by victims of non-consensual dissemination of intimate images. After analyzing the gender character of this practice, the data found in the jurisprudential research will be exposed and - considering the civilconstitutional doctrine - the reasoning of the decisions will be criticized.

Keywords: non-consensual dissemination of intimate images; revenge pornography; nonconsensual pornography; compensation; moral damages
} 


\section{Introdução}

A "pornografia de vingança" ou disseminação não consentida de imagens íntimas, designa a divulgação de fotos, imagens, vídeos, ou qualquer outro tipo de representação, de caráter sexual e privado, sem o consentimento de alguma das pessoas neles retratadas de forma identificável.

Apesar de existir há algum tempo - as primeiras ocorrências registradas remontam a 1980 e início dos anos $2000^{1}$-, essa prática ganhou maior repercussão apenas recentemente, com o uso da Internet como veículo de disseminação. Em plataformas e aplicativos virtuais de conexão dos internautas, além de o potencial de propagação das imagens e inflição de danos ser muito maior, é mais fácil a articulação de redes de indivíduos que se mobilizam para perseguir, assediar e ameaçar as vítimas de pornografia de vingança (SALTER, CROFTS, 2015, p.4).

Some-se a isso o caráter de violência de gênero dessa prática, que fica nítido não apenas quando se analisam as teorias feministas que explicam a posição da mulher na sociedade, como também quando se observam as estatísticas referentes às vítimas e os efeitos por elas sofridos.

De fato, diante de todas as consequências que esse tipo de violência tem sobre a vida e sobre a saúde psicológica especificamente da mulher, é preciso que as indenizações concedidas a título de danos morais reflitam tamanha gravidade, e que sua fundamentação seja respeitosa com os direitos fundamentais das vítimas.

Esse trabalho pretende demonstrar como o arbitramento - e a sua fundamentação - da compensação por danos extrapatrimoniais sofridos pelas vítimas de pornografia de vingança é ainda pouco sofisticado na tutela jurisdicional brasileira. É evidente a necessidade de se estabelecerem diretrizes de arbitramento que sejam condizentes com o tamanho do dano sofrido e que ofereçam algum senso de satisfação quanto à fundamentação do montante fixado.

O entendimento do que seja a pornografia de vingança, bem como a capacidade de compensar integralmente os danos dela advindos, passam pela compreensão de seu caráter de violência de gênero. Para tanto, será utilizada como base a teoria de Catharine MacKinnon sobre a desigualdade dos gêneros.

\footnotetext{
${ }_{1}^{1}$ Para um histórico da disseminação não consensual de imagens íntimas, ver BOUCHARDET, 2019. 


\section{Pornografia de vingança como violência de gênero}

É possível compreender, por meio da teoria de Catharine MacKinnon, que o significado que a sexualidade tem para a mulher é imensuravelmente distinto do que tem para o homem. Por ser socialmente construída, está permeada pela relação de poder existente entre os dois sexos e serve justamente à manutenção dessa estrutura. A sexualidade da mulher é apropriada pelo homem e usada para defini-la (MACKINNON, 2016, p. 801).

Sua tese, resumida nesses termos, é de que a moldagem, direção e expressão da sexualidade dividem a sociedade em dois sexos - homens e mulheres. Por sua vez, são as relações entre esses dois sexos que criam a sociedade. Portanto, trata-se de um ciclo em que o antecedente é causa do subsequente: por meio da sexualidade, há a criação de dois sexos, e as relações entre esses dois sexos estruturam a sociedade, que, novamente, determina a sexualidade.

Colocando em outros termos, a sexualidade é ferramenta das relações sociais desiguais: serve como um procedimento nas mãos de alguns - que detém mais poder e direitos - para determinar como será a dinâmica das relações. Assim é que esses sujeitos detentores do poder (homens) se apropriam da sexualidade de outros (mulheres), dirigindo-a e utilizando-a conforme queiram.

Em última instância, a organização da sexualidade por um dos lados significa que esse mesmo lado tem o poder de ditar qual será a realidade. Significa dizer que o masculino e o feminino existem na forma que os conhecemos porque o masculino assim os organizou. Ambos são definidos pela sexualidade: o homem, pelo modo que expressa sua sexualidade, e a mulher, pela forma como tem a sua sexualidade imposta sobre si pelo homem.

Assim, a disseminação não consensual de imagens íntimas é violência de gênero na medida em que se apoia sobre a definição social da mulher como sexo. A imposição sexual da pornografia de vingança já revela a violência de gênero: a sexualidade como forma de subordinação é imposta sobre as mulheres que aparecem nas imagens íntimas. Sua sexualidade, expropriada de si, cujo significado é atribuído por outros que não ela mesma, é usada como violência ${ }^{2}$.

\footnotetext{
2 Outros exemplos de experiências que revelam a definição social da mulher como sexo são a pornografia, a prostituição, o assédio sexual, o estupro, o incesto, a escravidão sexual feminina. Em todos eles, o que acontece é a imposição sexual. A sexualidade é uma forma de subordinação, de poder. Para serem violentos, a pornografia de vingança e os demais atos mencionados não precisam da força física, a imposição sexual por si só já lhes dá esse caráter. (MACKINNON, 2016, p. 819)
} 
Explicando a pornografia de vingança dentro da teoria feminista ${ }^{3}$, torna-se mais fácil perceber a dinâmica de poder existente na relação entre vítima mulher e perpetrador, mas, para entender por que a responsabilidade pela circulação de imagens íntimas recai sobre o corpo exposto e não sobre aquele que as fez circular (RINGROSE et al, 2013, p. 307), é necessário também analisá-la a partir do ponto de vista das vítimas.

O caráter de gênero dessa prática dificilmente seria apreendido dentro da epistemologia masculina, de distanciamento e pretensa imparcialidade e objetividade. Para a pornografia de vingança ser entendida tal como realmente é, o exame dos episódios em que ocorre deveria partir do lugar da vítima: do ponto de vista, da fala e do sofrimento da mulher que a vivencia.

Se não as desproporcionais estatísticas que indicam a ocorrência da pornografia não consensual majoritariamente com mulheres (EATON et al, 2017, pp. 13-14; POOLE, 2015, pp. 191-192; SAFERNET, 2019), os sentimentos experimentados pelas vítimas, bem como as reações que as imagens de seus corpos suscitam na coletividade - resultando em opressão em massa - são mais que suficientes para evidenciar o caráter de gênero.

De fato, é sabido que as vítimas da pornografia de vingança desenvolvem depressão; sofrem com vícios em álcool e outras drogas, experienciam terror noturno (WAKEFIELD, 2018), transtornos de estresse pós-traumático, precisam mudar seu nome, número de telefone, aparência, domicílio, trabalho, e até mesmo o domicílio de familiares ${ }^{4}$.

Para além disso, as reações desencadeadas em terceiros pela exposição de imagens íntimas de mulheres acusam o viés de gênero dessa violência. Depois de publicado o vídeo/foto na rede, é mais perceptível ainda a redução da mulher ao seu corpo, que sai totalmente de seu controle e é usado como justificativa para outras formas de violência: as vítimas comumente são xingadas de termos que atacam sua sexualidade ${ }^{5}$; assediadas, no trabalho e fora dele, por desconhecidos e conhecidos; contatadas com mensagens moralistas dizendo terem merecido o que a elas aconteceu ${ }^{6}$; perseguidas fora da Internet; exigidas em favores sexuais; e solicitadas para a prestação de programas.

\footnotetext{
${ }^{3}$ Aqui, utiliza-se "feminismo" como sinônimo da teoria de MacKinnon, para a fluidez da argumentação.

${ }^{4}$ No caso Rose Leonel, seu filho teve que mudar de país. O ex marido de Rose divulgava tanto dados pessoais da vítima, quanto da criança, que passou a também receber ligações.

${ }^{5}$ As agressões verbais estão em muitos relatos das vítimas à mídia. Pode-se citar como exemplo o caso Fran, o caso Rose Leonel e o caso Thamiris Sato.

${ }^{6}$ No episódio da divulgação de imagens íntimas da atriz Vanessa Hudgens, a empresa Disney Channel, para a qual trabalhava à época, emitiu pronunciamento dizendo que Hudgens agiu dessa forma por um "lapso de julgamento" e, esperava-se, teria aprendido uma valiosa lição com todo o acontecido. (NEWS, 2009).
} 
Ao final, todas essas reações e consequências desencadeadas pela disseminação de imagens íntimas buscam punir nada mais que a sexualidade da mulher. Sequer poderia ser dito que o julgamento coletivo sobre as vítimas recai apenas sobre as que manifestaram sua sexualidade livremente. Isso porque, mesmo os materiais nos quais a vítima não consente com o ato sexual, seja por expressa negativa, seja por estar inconsciente ${ }^{7}$, provocam insultos moralistas contra a sua sexualidade. $\mathrm{O}$ ódio desencadeado não tem como alvo uma falha de caráter da vítima; sua autonomia sexual ou o exercício de sua sexualidade, mas pura e simplesmente sua sexualidade em si.

Todas essas questões não poderiam ser identificadas sem uma análise de gênero. Assim é que o significado do que seja a pornografia de vingança varia conforme a maneira de apreensão da realidade. Tratar a pornografia de vingança como se não fosse uma questão de gênero significaria analisar a experiência da mulher através de outro: do dono de seu corpo, o homem (MACKINNON, 2016, p. 828). Seria focar em aspectos genéricos e ignorar o sofrimento tão característico que provoca nas mulheres - muito conectado à sua história e posição social. Analisar a vivência da mulher a partir da perspectiva do homem poderia levar à classificação da pornografia de vingança, por exemplo, como ofensa à honra da vítima ou somente à sua imagem, sem atentar às graves violações a aspectos da existência da mulher, como sua dignidade e liberdade.

A medida da identificação da pornografia de vingança, comum a todas as suas formas de divulgação, é a exposição de comportamentos considerados inadmissíveis pela moral sexual dominante, expondo a intimidade da vítima e apelando a repressões e ridicularização sociais. Em outras palavras, o objetivo da publicação do material - ou, mesmo quando não seja o objetivo, seu efeito mais imediato - é a exposição da intimidade de alguém e consequente repressão moralista posterior.

Portanto, a pornografia de vingança contra mulheres decompõe-se em duas partes: a primeira e mais evidente é a exposição da intimidade por si só; a segunda é a violência moral representada por esse ato e a violência coletiva por ele desencadeada. O enorme peso da pornografia de vingança - o que a diferencia de uma mera exposição da intimidade - é a segunda parte: a repressão moral que representa e que, comumente, suscita.

\footnotetext{
${ }^{7}$ Caso de Rehtaeh Parsons, a jovem canadense que foi fotografada sendo violentada sexualmente e, posteriormente à publicação das imagens, suicidou-se; e Chrissy Chambers, filmada por seu namorado, que a estuprava enquanto ela estava inconsciente.
} 
Dificilmente esse efeito da disseminação dos materiais afetará um homem que é identificado nos vídeos ou imagens. Isso porque comportamentos sexuais já são deles esperados; sua sexualidade não é um tabu.

O traço da repressão moralista é essencial à definição do ilícito: é o que o diferencia de uma mera violação de intimidade. De um lado, o que existe é a pura violação da intimidade que não desencadeia maiores consequências além de um constrangimento típico de quem foi exposto. De outro lado, a violação da intimidade que, por sua força atentatória à moral dominante, angaria esforços alheios para ridicularizar, reprimir, responder com violência e desrespeito àquela que foi exposta, à vítima. O punido não é o violador da intimidade, e sim quem teve sua intimidade violada. Essa constatação evidencia a deturpação do que acontece na disseminação não consensual de imagens íntimas de mulheres.

Delimitado o conceito da pornografia de vingança como violência de gênero, passa-se à exposição da pesquisa jurisprudencial.

\section{Tutela jurisdicional da disseminação não consensual de imagens íntimas: uma análise jurisprudencial}

Na etapa de coleta de dados desta pesquisa, foram consultados os sites dos tribunais de justiça dos Estados escolhidos e utilizadas apenas as decisões de segunda instância, pois são, em tese, a decisão final de um processo, voltados a corrigir eventuais erros de procedimento (error in procedendo) ou de julgamento (error in judicando) cometidos pelo juízo de primeiro grau, e, portanto, têm maior peso influenciando outros julgamentos.

Inicialmente, pretendia-se comparar as decisões de tribunais do sudeste com tribunais do sul do país. No entanto, por limitações metodológicas, optou-se por reduzir o grupo amostral e abranger apenas os acórdãos do Tribunal de Justiça do Rio Grande do Sul e do Tribunal de Justiça de São Paulo.

Apenas as decisões prolatadas por câmaras cíveis foram consideradas, uma vez que o objetivo é analisar as indenizações concedidas a título de danos morais. Além disso, foram desprezadas as demandas ajuizadas apenas em face de provedores de aplicação, ainda que indenizatórias. Não se trata de examinar a responsabilidade das empresas que disponibilizam 
plataformas virtuais ${ }^{8}$ para, por exemplo, a busca de conteúdo, mas sim dos perpetradores iniciais, aqueles que publicaram imagens íntimas sem o consentimento das vítimas.

A intenção foi examinar como os desembargadores fixam as indenizações por danos morais nos casos de pornografia de vingança, atentando à presença do viés de gênero nos casos levados até o judiciário e nas decisões, bem como ao arbitramento da indenização em si.

O resultado esperado era que os valores arbitrados a título de indenização por danos morais variassem drasticamente entre um acórdão e outro e entre uma instância e outra, principalmente porque (i) os casos que surgem no Judiciário dificilmente são parecidos, tendo as vítimas sofrido danos morais consideravelmente diferentes; e (ii) não há parâmetros objetivos para a fixação do valor compensatório. Também era esperado que os tribunais frequentemente reduzissem a indenização arbitrada pelo juízo de primeiro grau, diante da falta de compreensão de todos os aspectos da pornografia de vingança, notadamente seu caráter de violência de gênero. Por fim, quanto à fundamentação dos acórdãos, esperava-se que os magistrados não levassem em consideração a segunda parte da pornografia de vingança, isto é, a repressão moral representada e ensejada pela publicação das imagens, mas apenas a violação da imagem em si, publicada sem seu consentimento.

Descrita a metodologia empregada, passa-se à descrição dos resultados encontrados em cada um dos tribunais, dividida em "Viés de Gênero" e "Arbitramento das Compensações".

No site de cada tribunal, foram realizadas quatro buscas, conforme as palavras-chave utilizadas, compreendendo o período entre 2009 e 2019. Em cada uma delas, foram combinadas as expressões "fotos", "imagens", "vídeos", "íntimos" e "pornografia de vingança". No Tribunal de Justiça de São Paulo, foram encontrados 23 resultados pertinentes, e, no Tribunal de Justiça do Rio Grande do Sul, 24, abaixo listados:

\begin{tabular}{|c|c|}
\hline Tribunal de Justiça de São Paulo & Tribunal de Justiça do Rio Grande do Sul \\
\hline $\begin{array}{l}\text { Apelação } \quad \text { Cível } \\
\text { 04.2016.8.26.0100, Rel. Des. Natan Zelinschi } \\
\text { de Arruda, j. 02.05.2019 }\end{array}$ & $\begin{array}{l}\text { Apelação Cível no } 70049435415 \text {, Rel. Des. } \\
\text { Marcelo Cezar Muller, j. 27.09.2012 }\end{array}$ \\
\hline $\begin{array}{l}\text { Apelação } \quad \text { Cível } \mathrm{n}^{\circ} \text { 1047916- } \\
\text { 53.2013.8.26.0100, Rel. Des. Maia da Cunha, } \\
\text { j. 29.06.2017 }\end{array}$ & $\begin{array}{l}\text { Apelação Cível no } 70065184418 \text {, Rel. Des. } \\
\text { Eugênio Facchini Neto, j. 26.08.2015 }\end{array}$ \\
\hline $\begin{array}{l}\text { Apelação } \quad \text { Cível } \quad \mathrm{n}^{\circ} \quad \text { 0027776- } \\
\text { 68.2012.8.26.0320, Rel. Des. Alvaro Passos, j. } \\
\text { 22.11.2016 }\end{array}$ & $\begin{array}{l}\text { Apelação Cível no 70064472871, Rel. Des. } \\
\text { Eugênio Facchini Neto, j. 24.06.2015 }\end{array}$ \\
\hline
\end{tabular}

\footnotetext{
8 O Marco Civil da Internet - em seu artigo 21 - estabelece os limites da responsabilidade dos provedores no caso de disponibilização de conteúdos que violem a intimidade de alguém.
} 
BOUCHARDET, Carolina; OLIVIERA, Adriana Vidal de. Disseminação não consentida de imagens íntimas: uma análise jurisprudencial das compensações por danos morais.

\begin{tabular}{|c|c|}
\hline $\begin{array}{lccr}\text { Apelação } & \text { Cível } & \mathrm{n}^{\circ} & \text { 0090017- } \\
\text { 62.2012.8.26.0002, Rel. Des. James Siano, j. } \\
\text { 25.09.2014 }\end{array}$ & $\begin{array}{l}\text { Apelação Cível no 70033046574, Rel. Des. } \\
\text { Marilene Bonzanini, j. 28.04.2010 }\end{array}$ \\
\hline 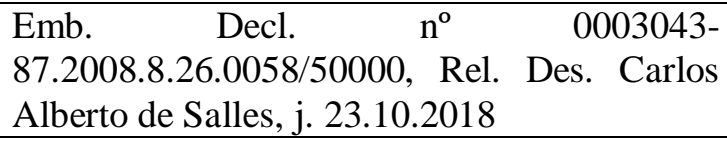 & $\begin{array}{l}\text { Apelação Cível no 70078417276, Rel. Des. } \\
\text { Catarina Rita Krieger Martins, j. 27.09.2018 }\end{array}$ \\
\hline $\begin{array}{lccr}\text { Apelação Cível } & \mathrm{n}^{\circ} & \text { 1023061- } \\
\text { 68.2016.8.26.0564, Rel. } & \text { Des. } & \text { Rosangela } \\
\text { Telles, j. 20.08.2018 } & & \\
\end{array}$ & $\begin{array}{l}\text { Apelação Cível no 70073274854, Rel. Des. } \\
\text { Catarina Rita Krieger Martins, j. 30.11.2017 }\end{array}$ \\
\hline \begin{tabular}{lcr} 
Emb. Decl. & $\mathrm{n}^{\circ}$ & \multicolumn{2}{c}{$0219648-$} \\
66.2006.8.26.0100/50000, Rel. & Des. José \\
Carlos Ferreira Alves, j. 31.07.2018 &
\end{tabular} & $\begin{array}{l}\text { Apelação Cível no } 70061298568 \text {, Rel. Des. } \\
\text { Túlio de Oliveira Martins, j. 27.11.2014 }\end{array}$ \\
\hline 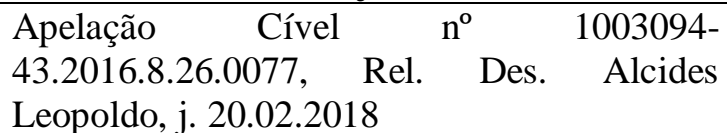 & $\begin{array}{l}\text { Apelação Cível no } 70052257532 \text {, Rel. Des. } \\
\text { Iris Helena Medeiros Nogueira, j. 12.12.2012 }\end{array}$ \\
\hline $\begin{array}{l}\text { Apelação } \quad \text { Cível } \quad \mathrm{n}^{\circ} \quad 0009890- \\
\text { 58.2013.8.26.0114, Rel. Des. Galdino Toledo } \\
\text { Júnior, j. 26.04.2016 }\end{array}$ & $\begin{array}{l}\text { Apelação Cível no 70065940439, Rel. Des. } \\
\text { Paulo Roberto Lessa Franz, j. 24.09.2015 }\end{array}$ \\
\hline $\begin{array}{l}\text { Apelação } \quad \text { Cível } \quad \mathrm{n}^{\mathrm{o}} \quad 9000022- \\
\text { 43.2010.8.26.0360, Rel. Des. Teixeira Leite, } \mathrm{j} \text {. } \\
\text { 02.10.2014 }\end{array}$ & $\begin{array}{l}\text { Apelação Cível no } 70050166776 \text {, Rel. Des. } \\
\text { Túlio de Oliveira Martins, j. 26.09.2013 }\end{array}$ \\
\hline $\begin{array}{l}\text { Apelação Cível } \mathrm{n}^{\circ} \quad \text { 0007475- } \\
\text { 86.2014.8.26.0108, Rel. Des. Hertha Helena } \\
\text { de Oliveira, j. 19.07.2018 }\end{array}$ & $\begin{array}{l}\text { Apelação Cível no 70054796867, Rel. Des. } \\
\text { Marcelo Cezar Muller, j. 01.08.2013 }\end{array}$ \\
\hline $\begin{array}{l}\text { Apelação } \quad \text { Cível } \text { n }^{\circ} \text { 1020457- } \\
\text { 61.2017.8.26.0577, Rel. Des. Rômolo Russo, } \\
\text { j. 27.06.2018 }\end{array}$ & $\begin{array}{l}\text { Apelação Cível no 70032280117, Rel. Des. } \\
\text { Jorge Luiz Lopes do Canto, j. 16.12.2009 }\end{array}$ \\
\hline $\begin{array}{lccc}\text { Apelação } & \text { Cível } & \mathrm{n}^{\circ} & 0002542- \\
\text { 68.2011.8.26.0272, Rel. } & \text { Des. } & \text { Eduardo Sá } \\
\text { Pinto Sandeville, j. } 20.10 .2016 & & \\
\end{array}$ & $\begin{array}{l}\text { Apelação Cível no 70070862073, Rel. Des. } \\
\text { Eugênio Facchini Neto, j. 23.11.2016 }\end{array}$ \\
\hline $\begin{array}{lcrr}\text { Apelação } & \text { Cível } & \mathrm{n}^{\mathrm{o}} & 0002263- \\
\text { 31.2013.8.26.0040, Rel. } & \text { Des. Walter Cesar } \\
\text { Exner, j. 22.06.2016 } & & \\
\end{array}$ & $\begin{array}{l}\text { Apelação Cível no } 70075919639 \text {, Rel. Des. } \\
\text { Niwton Carpes da Silva, j. 22.02.2018 }\end{array}$ \\
\hline $\begin{array}{l}\text { Apelação } \quad \text { Cível } \quad \mathrm{n}^{\circ} \quad 0004948- \\
\text { 60.2014.8.26.0368, Rel. Des. J.B. Paula Lima, } \\
\text { j. 03.05.2016 }\end{array}$ & $\begin{array}{l}\text { Apelação Cível no 70072678790, Rel. Des. } \\
\text { Paulo Roberto Lessa Franz, j. 28.06.2018 }\end{array}$ \\
\hline $\begin{array}{lccr}\text { Apelação } & \text { Cível } & \mathrm{n}^{\circ} & \text { 0219516- } \\
\text { 38.2008.8.26.0100, Rel. Des. Paulo Eduardo } \\
\text { Razuk, j. 29.10.2013 }\end{array}$ & $\begin{array}{l}\text { Apelação Cível } n^{\circ} \text { 70027861202, Rel. Des. } \\
\text { Túlio de Oliveira Martins, j. 26.11.2009 }\end{array}$ \\
\hline $\begin{array}{l}\text { Apelação Cível } \mathrm{n}^{\mathrm{o}} \quad r \quad 1008400- \\
\text { 96.2016.8.26.0269, Rel. Des. J.L. Mônaco da } \\
\text { Silva, j. 07.02.2018 }\end{array}$ & $\begin{array}{l}\text { Apelação Cível no 70079342010, Rel. Des. } \\
\text { Eugênio Facchini Neto, j. 18.12.2018 }\end{array}$ \\
\hline $\begin{array}{lllr}\text { Apelação Cível } & \mathrm{n}^{\mathrm{o}} & \text { 0015045- } \\
\text { 05.2012.8.26.0073, Rel. } & \text { Des. } & \text { Rosangela } \\
\text { Telles, j. 29.09.2015 } & & \\
\end{array}$ & $\begin{array}{l}\text { Apelação Cível no 70067051110, Rel. Des. } \\
\text { Carlos Eduardo Richinitti, j. 29.01.2016 }\end{array}$ \\
\hline $\begin{array}{l}\text { Apelação } \quad \text { Cível } \\
\text { 69.2010.8.26.0296, Rel. Des. Moreira Viegas, } \\
\text { j. 24.01.2018 }\end{array}$ & $\begin{array}{l}\text { Recurso Inominado } \mathrm{n}^{\circ} \text { 71006161913, Rel. } \\
\text { Des. Glaucia Dipp Dreher, j. 29.07.2016 }\end{array}$ \\
\hline $\begin{array}{l}\text { Apelação Cível } \quad \mathrm{n}^{\mathrm{o}} \quad \text { 0003141- } \\
\text { 93.2007.8.26.0224, Rel. Des. Rui Cascaldi, j. } \\
\text { 29.10.2013 }\end{array}$ & $\begin{array}{l}\text { Apelação Cível no 70077920544, Rel. Des. } \\
\text { Tasso Caubi Soares Delabary, j. 12.07.2018 }\end{array}$ \\
\hline 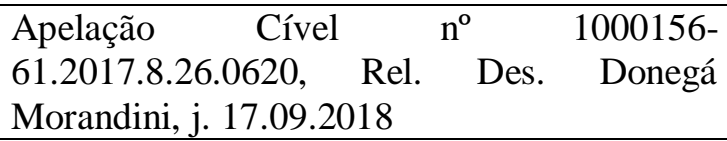 & $\begin{array}{l}\text { Apelação Cível no 70078201167, Rel. Des. } \\
\text { Marcelo Cezar Muller, j. 30.08.2018 }\end{array}$ \\
\hline
\end{tabular}


BOUCHARDET, Carolina; OLIVIERA, Adriana Vidal de. Disseminação não consentida de imagens íntimas: uma análise jurisprudencial das compensações por danos morais.

\begin{tabular}{|c|c|}
\hline $\begin{array}{l}\text { Apelação } \quad \text { Cível } \quad \mathrm{n}^{\mathrm{o}} \quad 0132309- \\
\text { 04.2008.8.26.0002, Rel. Des. Fábio Podestá, j. } \\
\text { 07.08.2013 }\end{array}$ & $\begin{array}{l}\text { Apelação Cível no } 70080275571 \text {, Rel. Des. } \\
\text { Paulo Roberto Lessa Franz, j. 28.03.2019 }\end{array}$ \\
\hline $\begin{array}{l}\text { Apelação } \quad \text { Cível } \quad \mathrm{n}^{\circ} \text { 9102480- } \\
\text { 25.2008.8.26.0000, Rel. Des. Coelho Mendes, } \\
\text { j. 29.01.2013 }\end{array}$ & $\begin{array}{l}\text { Apelação Cível } n^{\circ} \text { 70060691615, Rel. Des. } \\
\text { Jorge Alberto Schreiner Pestana, j. } \\
\text { 25.09.2014 }\end{array}$ \\
\hline & $\begin{array}{l}\text { Apelação Cível } \mathrm{n}^{\circ} \text { 70064243322, Rel. Des. } \\
\text { Jorge Alberto Schreiner Pestana, j. } \\
24.09 .2015\end{array}$ \\
\hline
\end{tabular}

\section{Viés de Gênero}

Infelizmente, os casos em que homens foram vítimas e chegaram ao Tribunal não ofereceram detalhes suficientes sobre o que ocorreu nem sobre as repercussões da divulgação das imagens, o que inviabiliza análises mais aprofundadas sobre essas hipóteses.

No Tribunal de Justiça de São Paulo, em apenas 13\% dos casos, homens foram as vítimas (3 acórdãos, do total de 23), enquanto em 87\% (20 acórdãos, do total de 23) mulheres tiveram suas fotos íntimas divulgadas. Já no Tribunal de Justiça do Rio Grande do Sul, somente $8 \%$ dos casos tiveram homens como vítima ( 2 acórdãos, do total de 24), enquanto $92 \%$ representavam mulheres (22 acórdãos, do total de 24).

$\mathrm{O}$ fato de mulheres serem alvo da pornografia de vingança em mais de $85 \%$ dos casos encontrados já confirma o caráter de violência de gênero dessa prática.

Soma-se a isso a constatação de que os casos de disseminação não consentida de imagens íntimas que chegam a esses tribunais comumente têm homens homossexuais como vítimas (em 3 dos 5 casos encontrados) $)^{9}$. Considera-se esse fator relevante para a compreensão da pornografia de vingança como questão de gênero, pois acaba por confirmar que, quando imagens íntimas de homens heterossexuais são divulgadas, existe uma violação à sua intimidade, mas dificilmente será um caso de pornografia de vingança.

Como já dito, a pornografia de vingança diferencia-se da mera violação da intimidade na medida em que suas consequências são mais pesadas e sua carga, moralista. Por isso, o conceito aqui adotado diz que existem duas partes nesse ilícito: a violação à privacidade - que ocorre com a disseminação da imagem íntima - e a repressão moral representada pela divulgação em si, já que a sexualidade exposta tem uma carga diferenciada, e pelas reações que enseja - que tomam as mais variadas formas, como, por exemplo, a perseguição e o assédio.

\footnotetext{
${ }^{9}$ Apelação Cível no 1023061-68.2016.8.26.0564, Rel. Des. Rosangela Telles, j. 20.08.2018 e Apelação Cível no 1047916-53.2013.8.26.0100, Rel. Des. Maia da Cunha, j. 29.06.2017. 
É relativamente fácil reconhecer que, quando um homem heterossexual é a vítima, em raras vezes existirá uma repressão moral coletiva daqueles que acessam as imagens divulgadas. Isso porque sua sexualidade não é vista com moralismo; pelo contrário, é normalizada desde a infância ${ }^{10}$. À mulher, por outro lado, é ensinado que deve manter-se casta; sentir culpa pelo exercício de sua sexualidade. Qualquer comportamento contrário a esse padrão é visto com reprovação - por vezes, escandalosa.

Ainda que se admita existirem relações homossexuais entre mulheres nas quais há subordinação, não foi encontrado qualquer caso em que a divulgação dos materiais tinha por vítima uma mulher homossexual. Por isso, é mais fácil a análise das situações nas quais homens homossexuais são as vítimas.

Segundo MacKinnon, o poder masculino é dos homens em princípio, mas há casos em que mulheres podem acessá-lo e casos em que homens podem perdê-lo (MACKINNON, 2013, p. 238). Dentro dessa lógica, o sexo homossexual entre homens seria visto como uma situação na qual os envolvidos são despidos do poder masculino. Assim, destituídos do papel de Sujeito, de subordinador, são colocados no papel seguinte: de Outro, subordinado. Sua sexualidade, por não consolidar todo o poder masculino próprio da heterossexualidade masculina, é usada como motivo para subordiná-los ${ }^{11}$.

Assim, como visto na fundamentação teórica inicial e confirmado pelos resultados da pesquisa no Tribunal de Justiça do Rio Grande do Sul, a disseminação de imagens íntimas é tipicamente praticada contra aqueles cuja sexualidade é moralmente julgada, subordinada. A pornografia de vingança só funciona como violência simbólica quando aquele que é exposto consegue ser efetivamente desvalorizado por sua sexualidade, o que ocorre sobretudo com mulheres e homossexuais.

\section{Arbitramento das compensações}

Os resultados confirmaram todas as expectativas, mas em diferentes graus. Os valores de indenização de fato variam drasticamente, especialmente no Tribunal de Justiça do Rio Grande do Sul, mas se mantém constantes no Tribunal de Justiça de São Paulo, que costuma manter as

\footnotetext{
${ }^{10}$ Simone de Beauvoir explica no segundo volume de O Segundo Sexo, como a sexualidade do homem e da mulher é moldada desde a infância (BEAUVOIR, 2016, p. 24).

${ }_{11}$ Daí, por exemplo, o uso da sexualidade de alguém para desacreditar seu familiar que concorre às eleições, como ocorreu na Apelação Cível no 70032280117, Rel. Des. Jorge Luiz Lopes do Canto, j. 16.12.2009. É improvável que o mesmo efeito fosse alcançado se as imagens mostrassem um homem em relações heterossexuais.
} 
decisões de primeiro grau. A redução das indenizações é recorrente, mas com menos frequência do que a majoração e a manutenção. Por fim, a fundamentação dos acórdãos raramente dá conta da gravidade da conduta e dos danos sofridos pelas vítimas, pois limitam-se a enumerar os direitos da personalidade violados - em sua maioria, imagem e honra - e citar os critérios vagos e genéricos já consagrados pela jurisprudência e pela doutrina para sustentar o valor arbitrado, sem preenchê-los com fatos ou princípios.

No Tribunal de Justiça do Rio Grande do Sul, em 7 decisões, o tribunal majorou a verba indenizatória arbitrada em primeiro grau; em 7, o montante inicial foi mantido; em 6, foi reduzido; em 2, foi mantida a improcedência; em 1, a indenização foi arbitrada inicialmente em segunda instância.

Os resultados mostram que, quando há majoração da indenização, os percentuais costumam ser bastante elevados. Dos 7 acórdãos em que houve majoração, em 4, o aumento do montante foi em percentual acima de $100 \%$ (135\%, 478\%, 233\% e 200\%), e nos outros 3, variaram consideravelmente $(26 \%, 66 \% \text { e } 88 \%)^{12}$. Mesmo nesses, o valor final arbitrado era elevado. Já nos casos de reduções, essas mantiveram-se ao redor de 30\%.

No Tribunal de Justiça de São Paulo, em 4 acórdãos, a indenização por danos morais foi arbitrada inicialmente em segundo grau; em 7, foi julgada improcedente pelo tribunal; em 8, o valor inicialmente arbitrado foi mantido em segunda instância; em 2, foi reduzido; e, em 2, a sentença foi anulada pelo tribunal e determinado o retorno do processo à primeira instância para a produção de provas. Como se vê, não há qualquer caso de majoração nem de supressão dos valores arbitrados inicialmente em primeira instância.

É importante registrar que, com os dados coletados, não foi possível analisar se o gênero da vítima influi ou não na quantia arbitrada a título de danos morais, porque a quantidade de casos em que homens são vítimas que chegam ao tribunal é reduzido demais, e os acórdãos que os julgam disponibilizam informações insuficientes para análises mais aprofundadas.

Confirmando as expectativas, a grande maioria dos casos não adentra nos efeitos subjetivos da disseminação não consensual de imagens íntimas e muito menos no caráter de violência simbólica de gênero. Os acórdãos costumam citar genericamente padrões doutrinários de fixação de indenização por danos morais, sem demonstrar como, no caso concreto, esses critérios se aplicam.

No reconhecimento dos danos morais, os acórdãos citavam sobretudo a ofensa ao direito à imagem e à honra, confirmando a expectativa de que os julgados costumam atribuir peso

\footnotetext{
12 Tais percentuais levam em consideração o valor nominal das indenizações.
} 
maior à imagem e à honra das vítimas no arbitramento dos danos morais. Se por um lado essa tendência é compreensível, visto que são parâmetros mais fáceis de serem aferidos objetivamente (pela repercussão das imagens da coletividade), por outro, podem ser indicações de que ainda existe um moralismo muito grande no Judiciário.

Se os acórdãos carecem de algo, seria o não reconhecimento da pornografia não consensual como violência simbólica de gênero. Os desembargadores se limitam a citar de forma genérica e superficial os padrões doutrinários de arbitramento dos danos morais, como as condições financeiras das partes e o caráter punitivo-pedagógico da indenização, sem os adequarem ao caso concreto.

\section{A importância de se adotar a doutrina civil-constitucional}

Com o surgimento do direito civil-constitucional e consequente transformação da ordem jurídica privada (MORAES, 2006, p. 234), a responsabilidade civil foi igualmente remodelada, e seus institutos ressignificados.

Ao longo da história, a função da responsabilidade civil era sobretudo de moralizar as condutas consideradas desviantes. Esse cenário, no entanto, foi modificado por ocasião da chamada virada principiológica da responsabilidade civil (MULHOLLAND, 2010, pp. 13-14), quando a proteção à pessoa humana, elevada ao ápice da pirâmide axiológica do ordenamento jurídico, teve como efeitos "a extensão da tutela da pessoa da vítima, em detrimento do objetivo anterior de punição do responsável” (MORAES, 2006, p. 238).

Uma das consequências mais importantes dessa mudança de paradigma foi a proeminência do dano injusto sobre o ato ilícito: "a reparação do dano sofrido, em qualquer caso, alcançou um papel muito mais relevante do que a sanção pelo dano causado" (MORAES, 2003, p. 13). Dessa maneira, começaram a aumentar as possibilidades de danos ressarcíveis (MORAES, 2006, p. 238).

Acompanhando a mudança do paradigma de valores, veio a constatação da historicidade dos institutos jurídicos: a eleição dos bens jurídicos a serem protegidos bem como da medida de sua proteção não decorre de evidências lógico-racionais, mas, na verdade, é determinada pela história (MORAES, 2003, p. 21). Essa assertiva poderia ser confirmada até mesmo pelo objeto dessa pesquisa: a responsabilidade civil por danos morais decorrente da divulgação de imagens íntimas seria inimaginável até poucos anos atrás, e já é reconhecida com facilidade, o que se explica pela gradual mudança de valores vigentes. 
Caso as decisões analisadas fossem alinhadas à leitura civil-constitucional da responsabilidade civil, pretendendo não avaliar a conduta do ofensor para puni-lo, mas antes examinar o dano injusto efetivamente vivido pela vítima, o arbitramento das compensações por danos morais seria, ou pareceria, muito mais justa e condizente com o caráter de violência de gênero da disseminação não consensual de imagens íntimas.

O grande equívoco cometido por quase todos os desembargadores nos acórdãos analisados é sobretudo a falta de especificidade nas fundamentações. Mesmo que façam alusão às "peculiaridades do caso concreto" e aos demais parâmetros de valoração, raramente indicam quais são, na demanda analisada, essas peculiaridades e parâmetros. Ao final, essa imprecisão acaba por deixar mais que evidente a arbitrariedade da valoração dos danos morais, porque a fundamentação vaga impede a análise externa e compreensão do que foi decidido (MORAES, 2003, p. 21).

\section{Conclusão}

Na esteira das constatações já feitas pela doutrina do direito civil-constitucional, chegase à conclusão de que o problema do arbitramento das indenizações está na fundamentação dos acórdãos encontrados: a vagueza dos critérios utilizados e a inadequação da função atribuída à compensação de danos morais leva a que os julgadores fixem valores que parecem contingências.

A extensão dos danos causados às vítimas não é compreendida sequer pela metade quando a preocupação dos julgadores é de apenas enumerar os direitos da personalidade expressos no artigo 20 do Código Civil. A análise objetiva dos direitos da personalidade violados deve ser conjugada com uma análise subjetiva, individualizada, dos danos causados às dimensões da dignidade da pessoa humana da vítima.

A fórmula discursiva de enumerar direitos personalíssimos como justificativa para o montante arbitrado impede a consideração de um dos traços mais importantes da pornografia não consensual: seu caráter de violência de gênero. A menção às peculiaridades do caso concreto tampouco tem o condão de, por si só, incluir no montante indenizatório a condição de mulher, por exemplo, traço extremamente diferenciador do dano sofrido.

Como já dito, os bens a serem tutelados pelo ordenamento jurídico e o grau de sua proteção variam conforme a dinâmica dos valores vigentes culturalmente. No contexto atual de reconhecimento das questões de gênero e progresso dos estudos sobre perspectivas de minorias, 
BOUCHARDET, Carolina; OLIVIERA, Adriana Vidal de. Disseminação não consentida de imagens íntimas: uma análise jurisprudencial das compensações por danos morais.

deveria ser natural a pretensão de protegê-las compreendendo seu sofrimento a partir da sua própria experiência.

Enquanto as verdadeiras peculiaridades do caso concreto não forem critérios para o arbitramento da compensação por danos morais, a pornografia de vingança não será compreendida como o que é - uma questão de gênero - e a magnitude do dano sofrido pelas vítimas não será refletido nas indenizações concedidas. 


\section{Referências bibliográficas}

BEAUVOIR, Simone de. O Segundo Sexo: A experiência vivida, vol. 2, $3^{\text {a }}$ ed. Rio de Janeiro: Nova Fronteira, 2016, p. 24.

BOUCHARDET, C. Disseminação não consensual de imagens intimas de mulheres: uma análise jurisprudencial do arbitramento de indenização por danos morais. 2019. 93f. Monografia (Graduação em Direito) - Faculdade de Direito, Pontifícia Universidade Católica do Rio de Janeiro. Rio de Janeiro, 2019.

EATON, Asia A.; JACOBS, Holly; RUVACALBA, Yanet. 2017 Nationwide Online Study of Nonconsensual Porn Victimization and Perpetration: A Summary Report. Cyber Civil Rights Initiative, 2017.

FIGHT THE NEW DRUG. Italian Woman Commits Suicide One Year After Sex Tape Unexpectedly Goes Viral.

FRANKS, M. A. "Revenge Porn” Reform: A View from the Front Lines. Florida Law Review, Forthcoming. University of Miami Legal Studies Research Paper No 16-43, pp. 1251-1337.

MACKINNON, Catharine. Feminismo, Marxismo, Método e o Estado: Uma agenda para a teoria (tradução de Juliana Carreiro Avila e Juliana Cesario Alvim Gomes). Revista Direito e Práxis. Rio de Janeiro, v. 7 n. 15, 2016.

MACKINNON, Catharine. Desejo e Poder. In: MIGUEL, Luis Felipe; BIROLI, Flávia (Org.). Teoria política feminista: textos centrais. Vinhedo: Editora Horizonte, 2013.

MORAES, Maria Celina Bodin de. O jovem direito civil-constitucional. Civilistica. com: revista eletrônica de direito civil, v. 1, n. 1, 2012.

MORAES, Maria Celina Bodin de. A constitucionalização do direito civil e seus efeitos sobre a responsabilidade civil. Revista Direito, Estado e Sociedade, v. 9, nº 29, jul./dez. 2006.

MORAES, Maria Celina Bodin de. Danos à pessoa humana: uma leitura civil-constitucional dos danos morais. Rio de Janeiro: Renovar, 2003.

MULHOLLAND, Caitlin Sampaio. A responsabilidade civil por presunção de causalidade. Rio de Janeiro: CZ Ed., 2010.

NEWS. "Nude photo of Vanessa Hudgens circulates the internet".

POOLE, Emily. Fighting Back Against Non-Consensual Pornography. University of San Francisco Law Review, vol. 49, issue 1, nov. 2015.

SAFERNET. Indicadores Helpline.

RINGROSE et al. "Teen girls, sexual double standards and 'sexting': Gendered value in digital image exchange", p. 307 
SALTER, M.; CROFTS, T. Responding to Revenge Porn: Challenges to Online Legal Impunity. In: CORNELLA, L; TARRANT, S. (editors). New Views on Pornography: Sexuality, Politics and the Law. Westport: Praeger Publisher, 2015.

WAKEFIELD, Jane. "Revenge Porn Almost Killed Me". $B B C$. 